\title{
Non-histaminic angioedema
}

INSERM

\section{Source}

INSERM. (1999). Orphanet: an online rare disease and orphan drug data base. Nonhistaminic angioedema. ORPHA:658

Angioedema is characterized by the occurrence of transitory and recurrent subcutaneous and/or submucosal edemas resulting in swelling and/or abdominal pain. 